\title{
Optimal System for Improved Internal Model Control of Argon-Oxygen Decarburization Process Based on the Piecewise Linear Model and Time Constant of Filter Optimization
}

\author{
Changjun Guan $(\mathbb{D})$ and Wen You \\ School of Electrical and Electronic Engineering, Changchun University of Technology, Changchun 130012, China \\ Correspondence should be addressed to Changjun Guan; guanchangjun197951@163.com
}

Received 18 September 2021; Revised 3 December 2021; Accepted 18 December 2021; Published 3 January 2022

Academic Editor: Luis J. Yebra

Copyright (C) 2022 Changjun Guan and Wen You. This is an open access article distributed under the Creative Commons Attribution License, which permits unrestricted use, distribution, and reproduction in any medium, provided the original work is properly cited.

\begin{abstract}
This paper presents an improved internal model control system to raise the efficiency of refining low-carbon ferrochrome. This control system comprises of a piecewise linearized transfer function and an improved internal model controller based on optimized time constant of the filter. The control system is mainly used to control the oxygen supply rate during the argon-oxygen refining for controlling the smelting temperature. The regulatory performance and servo of two closed-loop control schemes are compared between the improved internal model controller based on the optimized filter time 0000-0002-7606-6546and the internal model controller based on the fixed filter time constant. The simulation analysis shows that the piecewise linearized model and the optimization of the time constant of the filter improves the response time, stability, and anti-interference ability of the controller. Then, the proposed improved internal model controller is used to adjust the gas supply flow in 5 ton AOD furnace to control the smelting temperature. Ten production tests performed the effectiveness of the controlling refining optimal system. The analysis of the experimental data shows that the improved internal model control system can shorten the melting time and improve the melting efficiency. Thus, the application of the improved internal model control system in low-carbon ferrochrome refining is an interesting potential direction for future research.
\end{abstract}

\section{Introduction}

With the rapid development of industrial process, the controlled object models become more and more complex. Many actual industrial processes are multivariable [1]. The complexity of the model of the controlled object increases, which leads to slow compensation and response of the system. The argon-oxygen decarburization (AOD) process is one of the most common processes for refining medium and low-carbon ferrochromium [2]. The temperature control of AOD process is influenced by many factors, such as the composition of the molten pool, the rate of oxygen and argon injection, the mixing degree of the molten pool, and the fluidity of the melting slag [3]. The refining temperature control in AOD process has the characteristics of multivariable, large lag, inaccurate mathematical model, and nonmeasurable strong disturbance [4]. The important practical considerations in control structure selection are to ensure that the selected controller does not depend on the exact model and has good disturbance resistance.

Internal model control (IMC) is one of many methods to design controllers. It has been proved to be a powerful control method for multivariable systems [5], and it shows an advantage in theoretical analysis of the stability and robustness of control system, especially in the control of large time delay systems [6]. Therefore, it is frequently applied in the process control with a slow response. The basic design idea of IMC is to combine an optimal controller obtained from the nominal process model with a low-pass filter to tradeoff closed-loop performance with robustness to model uncertainties. Furthermore, the IMC control structure allows for separate controller design for performance and robustness to alleviate the tradeoff between performance and robustness in the traditional feedback framework [7]. In recent years, increasingly, research has been 
done on the application of IMC. Ali et al. presented a general IMC structure with multiple degrees of freedom for the design of control systems with multiple objectives; the control structure is demonstrated on a simulated thin-film drying process in continuous pharmaceutical manufacturing for several multiloop control structures [8]. Jiang et al. [9] proposed an IMC method based on a damped pseudoinverse, and an analysis was made to evaluate the stability of the system. Qiu et al. [10] proposed a modified stability-constrained identification method with established boundedness and continuity properties and demonstrated the effectiveness of the proposed algorithm with an example. Although the IMC method has been widely studied and applied, the application of the IMC is restricted when strong load disturbance exists or stable control accuracy and response speed are highly required in the system. To realize the unbiased tracking of the system and eliminate the influence of the disturbance on the system, a low-pass filter is required in series with the controller. The filter time constant is one of the important factors affecting the controller's speed and robustness [11].

In this paper, an IMC method based on the piecewise identification model and particle swarm optimization filtering time parameter is developed. First, the refining process is divided into three stages according to the carbon content in the molten pool, and the piecewise linear model based on the advantages of model identification technology is obtained [12]. Then, the IMC is designed with the transfer function of the real object identified. Based on the deviation of the IMC, the integrated time absolute error ITAE is used as the fitness function of the particle swarm optimization algorithm. The particle swarm optimization is used to determine the filtering time constant. The filter time constant obtained by particle swarm optimization can ensure that our estimation result is robust and less influenced by the imprecision of the model, which can maintain high efficiency. The inference for all parameters is directly derived by using existing theories. Simulation experiments are conducted to evaluate the response performance and anti-interference performance of the control method and investigate the finite sample performance of the proposed method. Finally, the effectiveness of the proposed control system is summarized.

\section{Transfer Function of Temperature Control System for Argon-Oxygen Refined Ferrochrome}

The reaction of argon-oxygen refining ferrochrome occurs in normal pressure and high temperature environment. The temperature is an important technological parameter in the refining of low-carbon ferrochrome by argon-oxygen decarburization [13]. The refining process is the dynamic equilibrium of high temperature chemical reactions. The main chemical reactions can be described with (1)-(4) [12-14]:

$$
\begin{aligned}
& 2[C]+\left\{O_{2}\right\}=2\{C O\}, \\
& 2\left[S_{i}\right]+\left\{O_{2}\right\}=2\left(S_{i} O_{2}\right),
\end{aligned}
$$

$$
\begin{gathered}
2[\mathrm{Fe}]+\left\{\mathrm{O}_{2}\right\}=2(\mathrm{FeO}), \\
4[\mathrm{Cr}]+3\left\{\mathrm{O}_{2}\right\}=2\left(\mathrm{Cr}_{2} \mathrm{O}_{3}\right),
\end{gathered}
$$

where [ ] means it is dissolved melt, \{\} means it is gaseous phase, and ( ) means it is slag phase.

In a previous work, improvements have been made on the mathematical model of the AOD refining process proposed by Guan and You [15]. The mathematic model of temperature control that gives the relationship between the carbon content and the oxygen supply rate was obtained. According to the characteristics of argon-oxygen refining process [16], the piecewise linearization treatment of the mathematic model was carried out. Temperature control models of the three refining stages are obtained by fitting to the production data. The transfer function of temperature control in three stages were developed for the AOD furnace as follows.

For the first stage,

$$
G_{p 1}(s)=\frac{T(s)}{O(s)}=\frac{2.13}{1.77 s+1} e^{-20 s} .
$$

For the second stage,

$$
G_{p 2}(s)=\frac{T(s)}{O(s)}=\frac{5.55}{10.80 s+1} e^{-20 s} .
$$

For the third stage,

$$
G_{p 3}(s)=\frac{T(s)}{O(s)}=\frac{15.34}{25.88 s+1} e^{-20 s} .
$$

\section{Design and Implementation of an Internal Model Controller}

3.1. IMC Structure. IMC is widely used in the process with measurable outputs and nonmeasurable disturbances [17]. The block diagram of the IMC system [18] is shown in Figure 1.

As shown in Figure 1, R(s) is the input, $\mathrm{Y}(\mathrm{s})$ is output, $\mathrm{G}_{\mathrm{c}}(\mathrm{s})$ is the inferential controller, $\mathrm{G}_{\mathrm{pi}}(\mathrm{s})$ is the process channel transfer function, $G_{m}(s)$ is the process channel estimation model, $\mathrm{V}(\mathrm{s})$ is the disturbance channel transfer function, $\widehat{Y}(s)$ is the estimate value of $Y(s)$, and $\widehat{V}(s)$ is the estimate value of $\mathrm{V}(\mathrm{s})$.

From Figure 1, the system output is calculated as below:

$$
\begin{aligned}
Y(s)= & \frac{G_{c}(s) G_{p i}(s)}{1+G_{c}(s) G_{p i}(s)-G_{c}(s) G_{m}(s)} R(s) \\
& +\frac{1-G_{c}(s) G_{m}(s)}{1+G_{c}(s) G_{p i}(s)-G_{c}(s) G_{m}(s)} V(s) .
\end{aligned}
$$

The temperature control system output of low-carbon ferrochrome refining process in AOD furnace can be measured, while the temperature influence of argon gas is not measurable. Thus, the influence of argon gas on temperature can be regarded as the system disturbance. The control law is derived through mathematical reasoning [19]. Because the minimum phase part 


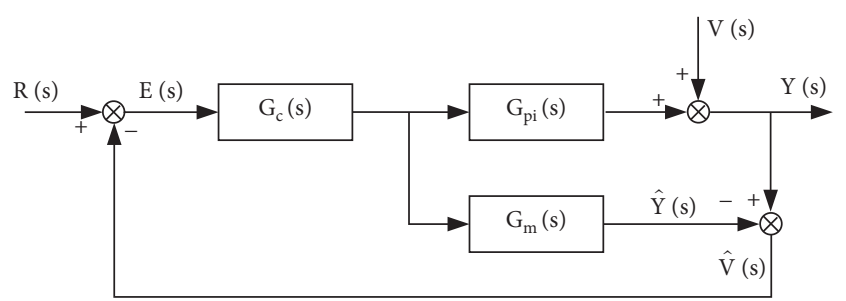

FIgURE 1: The structure diagram of IMC.

of the first-order inertia-hysteresis model is stable, it can meet the requirement of design the internal model controller [20]. The mathematical model of temperature control in the argonoxygen refining process with system identification is used as the transfer function of the actual object. $G_{p i}(s)$ is the mathematical expression.

There is a lag component in the model with temperature as the actual control object, which is a nonminimum phase component, and then, $\mathrm{G}_{\mathrm{c}}(\mathrm{s})$ will contain a lead component, while the ideal controller cannot realize the dynamic compensation completely. To solve this problem, the object model can be designed as follows [21]:

$$
G_{p i}(s)=G_{m}(s)=G_{m+}(s) G_{m-}(s),
$$

where $G_{m+}(s)$ is the stable part of the minimum phase component, $\mathrm{G}_{\mathrm{m}-}(\mathrm{s})$ is the nonminimum phase component with time delay and zeros of right-half-plane.

When the system's parameters change, the model does not match the system. To overcome model mismatch, $\mathrm{G}_{\mathrm{c}}(\mathrm{s})$ has important roles. $G_{c}(s)$ is set as shown in formula (10). It can improve the stability and robustness of the system:

$$
G_{c}(s)=G_{f}(s) \cdot G_{m+}^{-1}(s),
$$

where $G_{f}(s)$ is the transfer function of the filter with firstorder inertia component. filter.

$G_{f}(s)=1 / \lambda s+1$, where $\lambda$ is the time constant of the

Then, the system output can be expressed as follows:

$$
Y(s)=G_{f}(s) G_{m-}(s) R(s)+\left(1-G_{f}(s) G_{m^{-}}(s)\right) V(s) .
$$

When a large mismatch exists between the model and the plant, $\lambda$ should be taken as a big value, which can avoid the oscillation of the output signal. If the degree of mismatch is small between the model and the plant, $\lambda$ should be taken as a small value, which can improve the response speed of the system [22]. If $\lambda$ is suitable, the control model improves the system's response time, stability, and anti-interference ability [23].

3.2. Filter Time Constant Determination. It is a key problem for the rapidity and robustness of the controller to determine the filter time constant [24]. Eber-hart and Kennedy proposed particle swarm optimization (PSO) in 1995 [25], which is a global stochastic optimization technique for continuous methods. The ultimate purpose of this algorithm is to have whole particles find the optima in the high-dimensional data volume. To find the optima, each particle follows its previous best placement. The PSO technique will refurbish the velocity and the position of each particle. The velocity and position updating operations in PSO are as stated follows:

$$
\begin{aligned}
v_{i d}(k+1)= & \omega v_{i d}(k)+c_{1}\left(p_{i d}(k)-x_{i d}(k)\right) R_{1 i d} \\
& +c_{2}\left(g_{i d}(k)-x_{i d}(k)\right) R_{2 i d}, \\
x_{i d}(k+1)= & x_{i d}(k)+v_{i d}(k+1),
\end{aligned}
$$

where $v_{i d}(k+1)$ and $v_{i d}(k)$ denote the velocities in the $t+1$ th and $t$ th iterations, respectively, $x_{i d}(k+1)$ and $x_{i d}(k)$ represent the positions of the particle $i$ in the $d$ th dimension in $t+1$ th and $t$ th iterations, respectively, $\omega$ is the inertia weight to stabilize the local and global search, $R_{1 i d}$ and $R_{2 i d}$ are random vectors, and $c_{1}$ and $c_{2}$ are the acceleration coefficients. Moreover, $p_{i d}(k)$ and $g_{i d}(k)$ represent the personal best solution of the particle $i$ and the global best solution in the $d$ th dimension, respectively.

Usually, $c_{1}+c_{2} \leq 4$; in this paper, $c_{1}=c_{2}=2$. The particle swarm optimization is updated iteratively, and the global optimal value is finally obtained.

Using particle swarm optimization algorithm to optimize the filter time constant, $x=\lambda$. The purpose of optimizing the controller parameters is to make the static difference tend to zero. Therefore, the response of the system has a short regulation time and small overshoot.

If the number of particles in the initialized population is $\mathrm{N}$, each particle in the swarm conserves a form of a matrix; it is shown as follows:

$$
P=\left[\begin{array}{c}
\lambda_{1} \\
\vdots \\
\lambda_{N}
\end{array}\right]
$$

The selection of fitness function directly affects the convergence rate of PSO. Control system design using ITAE has the advantages of small overshoot, moderate damping, and good dynamic performance, so ITAE is often used to measure system performance in the control field [26]. ITAE index is used as the fitness function of particle swarm optimization algorithm in a long-time delay system. The fitness function is shown as

$$
J=\frac{1}{\int_{0}^{t} t|e(t)| d t} .
$$

The steps of PSO algorithm are as follows:

(1) Swarm has to be initialized by assigning a position, $N=40 . \mathrm{d}$ is the dimension of the particle, $d=1$. $\omega$ decreases with the number of iterations, and the formula is as follows [27]:

$$
\omega=\omega_{\min }+\left(\omega_{\max }-\omega_{\min }\right) \frac{\text { iter }_{\max }-\text { iter }}{\text { iter }_{\max }},
$$

where iter is the current iteration of the algorithm and iter $_{\max }$ is the maximum number of iterations; the PSO is allowed to continue. 
(2) The initial value is substituted into equations (12) and (13) to get a better position and speed.

(3) Fitness function is estimated for each particle. Compare the particle's fitness value with the personal optimal value for each individual particle.

(4) If the current value is better than the previous personal optimal value, then set this as the global optimal value for the current particle's position.

(5) Until a sufficiently good fitness value is achieved, repeat step 2 .

3.3. Filtering Time Constant of the Piecewise Model. The structure diagram of the simulation experiment is shown in Figure 2. Firstly, the carbon content in the bath was detected by a laser-induced breakdown spectroscopy instrument [28]. The internal model controller judges the refining stage by detecting the value of carbon content. The integral of time-weighted absolute error (ITAE) performance index has the advantage of producing small overshoots and oscillations [29]. It has been chosen as the objective function applied to optimize the filter time constant. The filter time constant was optimized by particle swarm optimization algorithm according to the initial deviation of the piecewise model. The filtering time constant is shown in Table 1. According to the detected carbon content, the internal model controller selects the filtering time constant of the corresponding piecewise model from Table 1. The optimized filtering time constant can improve the rapidity and robustness of the system response.

\section{Simulation Analysis}

4.1. Analysis of Rapidity and Stability. In this section, we compare the regulatory performance as well as the servo of two closed-loop control schemes, namely, the improved internal model controller based on optimized time constant of the filter and the previous work of the internal model controller based on fixed time constant of the filter [30]. The Simulink simulation model is shown in Figure 3. It should be noted that here a piecewise model variation is imposed on the manipulated variable (i.e., oxygen rate) that is quite reasonable from the practical aspect. In the process of argonoxygen refining of low-carbon ferrochrome, the temperature is controlled at $1700-1800^{\circ} \mathrm{C}$ [31]. According to the change of carbon content, the refining process is divided into three stages [32]. The proportion of the mixed gas varies at each stage. When the two stages are switched, the equilibrium state of the previous stage is changed because the mixture ratio changes. This is equivalent to setting a new value. The temperature control curve is obtained through simulation; it is shown in Figure 4.

According to the refining process, the initial temperature of the chromite molten liquid in the furnace is about $1400^{\circ} \mathrm{C}$, and the refining temperature is controlled at about $1700^{\circ} \mathrm{C}$ [33]. In the simulation study, we introduce a step change in the initial point from $1400^{\circ} \mathrm{C}$ to $1700^{\circ} \mathrm{C}$. In this case study, the internal model controller based on fixed time constant of the filter (FTC) shows a big overshoot with a decayed oscillation (see Figure 3). On the contrary, this improved internal model controller based on optimized time constant of the filter (OTC) shows a satisfactory servo performance. To clearly see the performance indexes, the transient process of the three stages is enlarged from Figures 5-7. It is obvious from Figures 5-7 that the proposed controller is superior to the previous work of the internal model controller based on fixed time constant of the filter. This is also evident from the quantitative analysis made in Table 2 based on the ITAE values. The performance indexes of the control system are shown in Table 2.

The simulation results show that the improved internal model controller based on optimized time constant of the filter has better performance than the internal model controller based on fixed time constant of the filter in terms of speed and stability.

4.2. Antidisturbance Analysis. In the simulation study, we introduce two consecutive step changes in the set point (a step increases from 0 to 8 at time $=0 \mathrm{~s}$ and thereafter, a step decreases from 0 to -8 at time $=1000 \mathrm{~s}$ ). They are perturbance. The internal model controller based on fixed time constant of the filter eliminates the perturbance after $300 \mathrm{~s}$, while the improved internal model controller based on optimized time constant of the filter eliminates the perturbance after $200 \mathrm{~s}$. In this case study, the internal model controller based on fixed time constant of the filter shows a big overshoot with a decayed oscillation (see Figure 8). It is obvious from Figure 8 that the proposed controller is superior to the previous work of the internal model controller.

As shown in Figure 9, a sinusoidal wave disturbance signal is added. It can be seen from the amplitude that the improved internal model controller based on optimized time constant of the filter has a better effect on disturbance suppression. Through simulation analysis, both control methods are effective for disturbance signals, but the improved internal model controller based on optimized time constant of the filter shows better antidisturbance performance than the other one.

\section{Experiment Results and Analysis}

5.1. Validation Material. The proposed improved internal model controller is used to adjust the gas supply flow in 5 ton AOD furnace to control the smelting temperature. The furnace is fitted with two bottom-blowing and a top lance. In contemporary practice, both a top lance and tow bottom lances are employed for delivering the required oxygen into the melt in combined top-blowing and bottom-blowing decarburization. Ten validation heats were conducted. In the operating practice, the combinedblowing stage is divided into steps, which differ in terms of the employed blowing mixture. In the studied heats, the last combined-blowing stage was altered so that oxygen was introduced from the bottom lance only. The computer control interface is shown in Figure 10. The validation heat site is shown in Figure 11. 


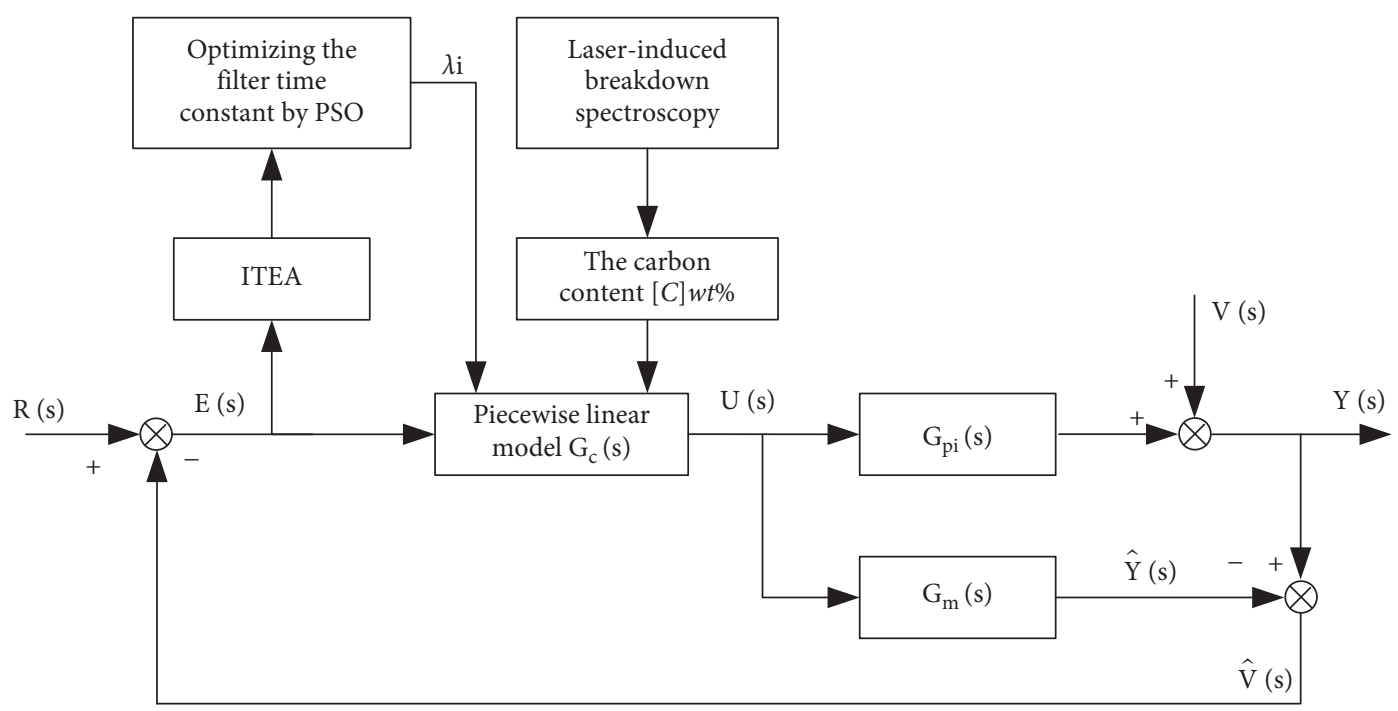

FIGURE 2: Inference extended model control structure based on piecewise model identification and particle swarm optimization algorithm.

TABLE 1: The filter time constant of the piecewise model.

\begin{tabular}{lccc}
\hline Carbon content $[\mathrm{C}] \mathrm{wt} \%$ & Process channel transfer function, $\mathrm{G}_{\mathrm{pi}}(\mathrm{s})$ & $\mathrm{ITAE}$ & Filter time constant, $\lambda$ \\
\hline$[\mathrm{C}] \mathrm{wt} \% \geq 2 \%$ & $\mathrm{G}_{\mathrm{p} 1}(\mathrm{~s})$ & $\int_{0}^{\mathrm{t}} \mathrm{t}\left|\mathrm{e}_{1}(\mathrm{t})\right| \mathrm{dt}$ & $\lambda_{1}$ \\
$2 \%>[\mathrm{C}] \mathrm{wt} \% \geq 1 \%$ & $\mathrm{G}_{\mathrm{p} 2}(\mathrm{~s})$ & $\int_{0}^{\mathrm{t}} \mathrm{t}\left|\mathrm{e}_{2}(\mathrm{t})\right| \mathrm{dt}$ & $\lambda_{2}$ \\
$1 \%>[\mathrm{C}] \mathrm{wt} \% \geq 0.2 \%$ & $\mathrm{G}_{\mathrm{p} 3}(\mathrm{~s})$ & $\int_{0}^{\mathrm{t}} \mathrm{t}\left|\mathrm{e}_{3}(\mathrm{t})\right| \mathrm{dt}$ & $\lambda_{3}$ \\
\hline
\end{tabular}

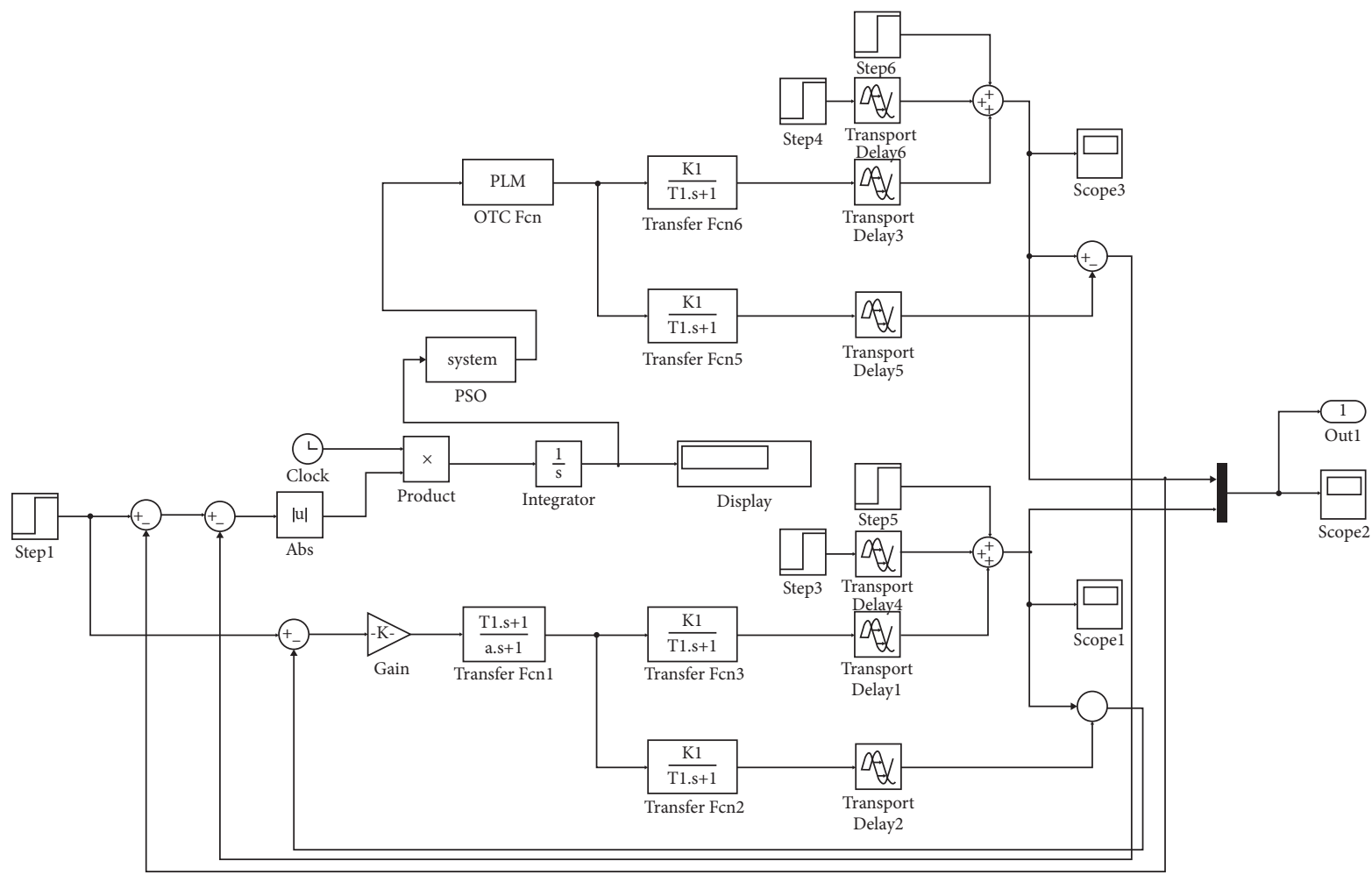

Figure 3: Simulink simulation model. 


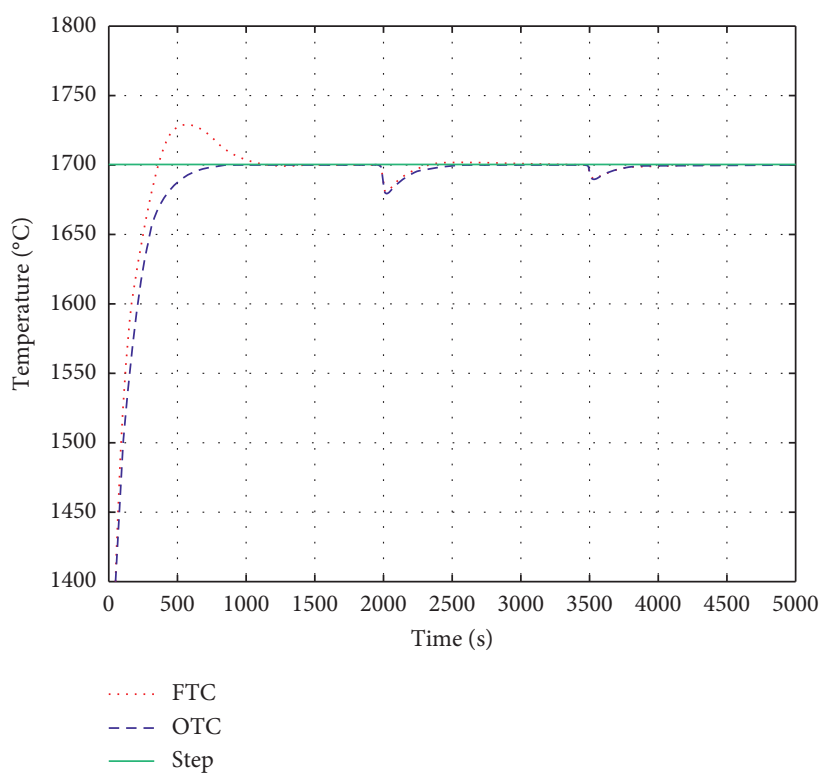

Figure 4: Temperature control curve.

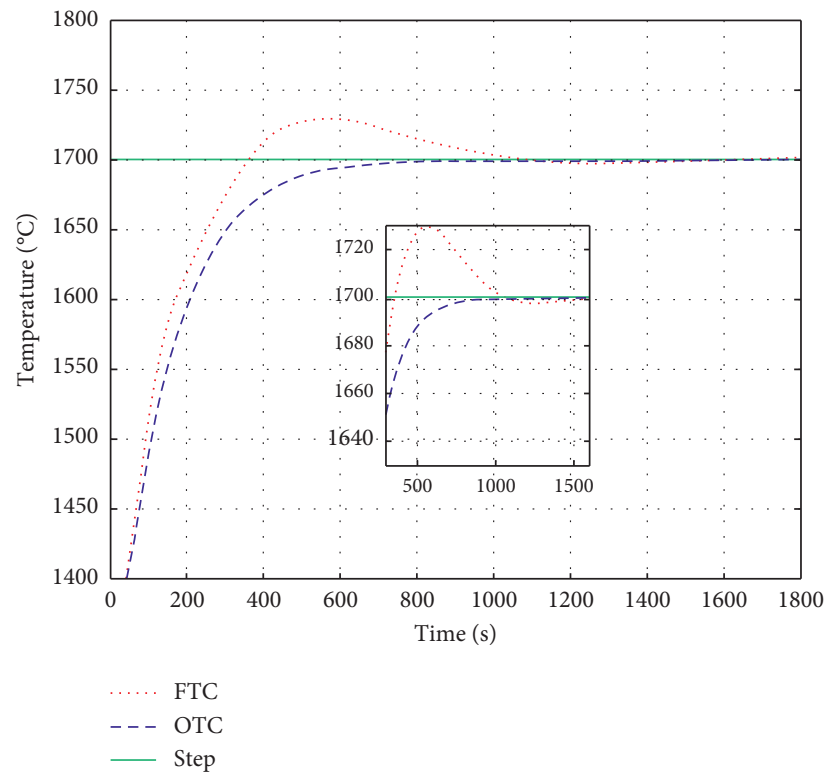

FIgURE 5: Temperature control curve of the first refining stage. 


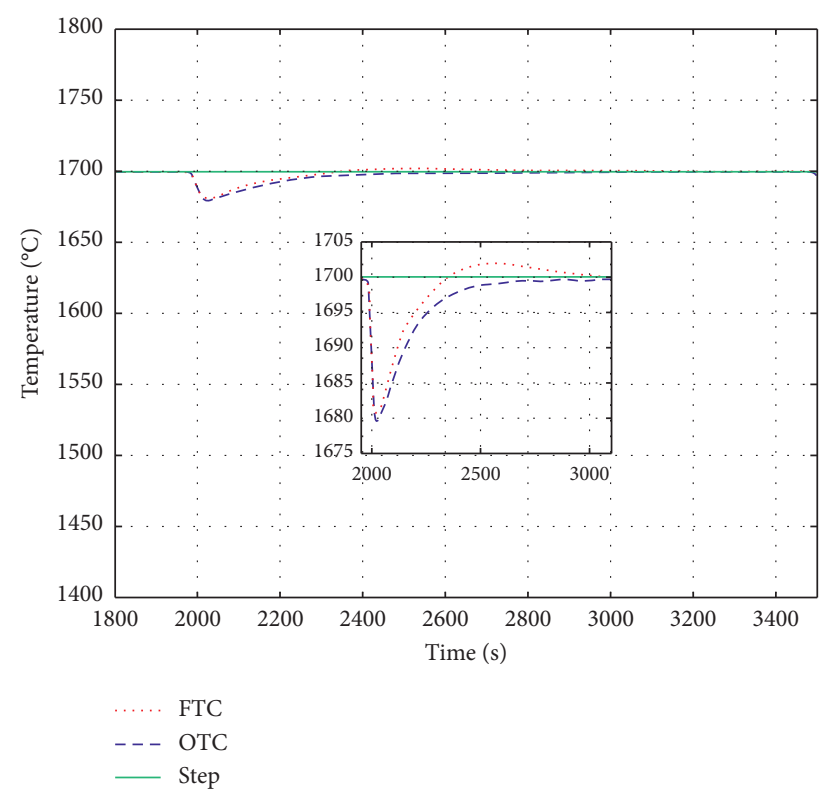

Figure 6: Temperature control curve of the second refining stage.

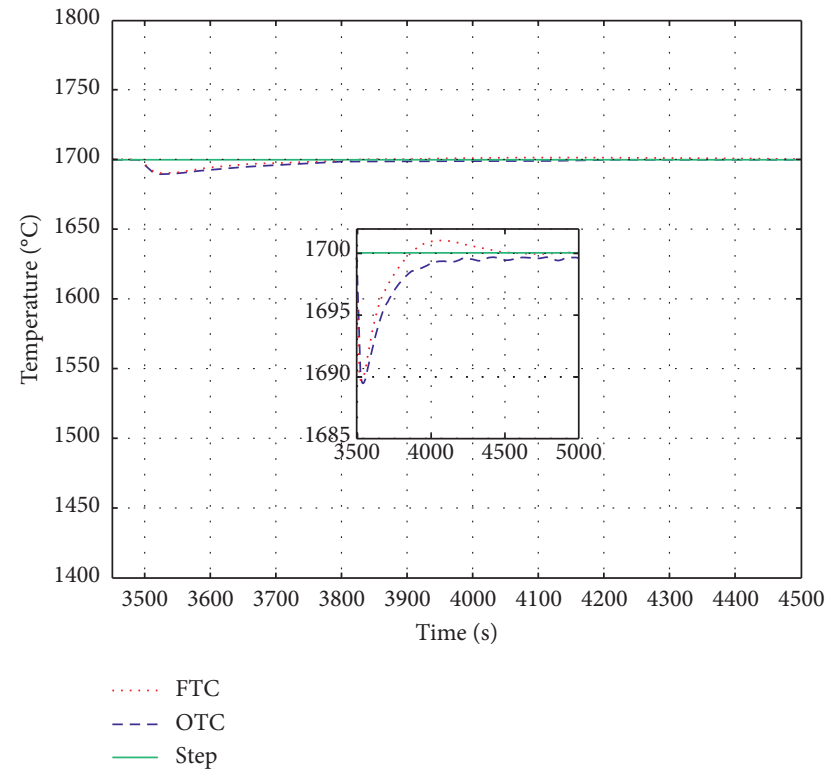

Figure 7: Temperature control curve of the third refining stage.

Table 2: Performance indexes of the control system.

\begin{tabular}{|c|c|c|c|c|c|c|}
\hline \multirow{2}{*}{ Control scheme } & \multicolumn{3}{|c|}{ The overshoot } & \multicolumn{3}{|c|}{ Adjust the time (s) } \\
\hline & 1 stage & 2 stage & 3 stage & 1 stage & 2 stage & 3 stage \\
\hline FTC & $10 \%$ & $5 \%$ & $6 \%$ & 1030 & 800 & 900 \\
\hline OTC & 0 & 0 & 0 & 780 & 400 & 500 \\
\hline
\end{tabular}

5.2. Experimental Data Analysis. The carbon content, furnace temperature, and unit refining time for the ten tests are presented in Table 3.

The average unit refining time of the ten experiments was $14.51 \mathrm{~min}$.
Without the use of the improved IMC method, the average unit refining time of the carbon content control was 18.43 min. From Figure 12, the average smelting time of the ten experiments with the improved IMC method reduced by $21.27 \%$ compared with that without the improved IMC 


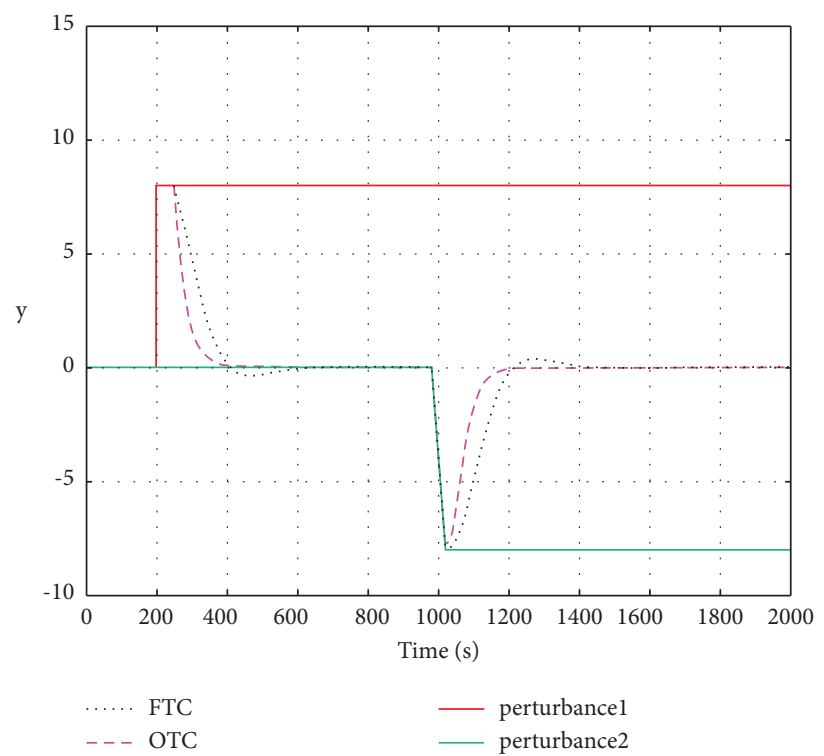

FiguRE 8: Suppressed step disturbance performance.

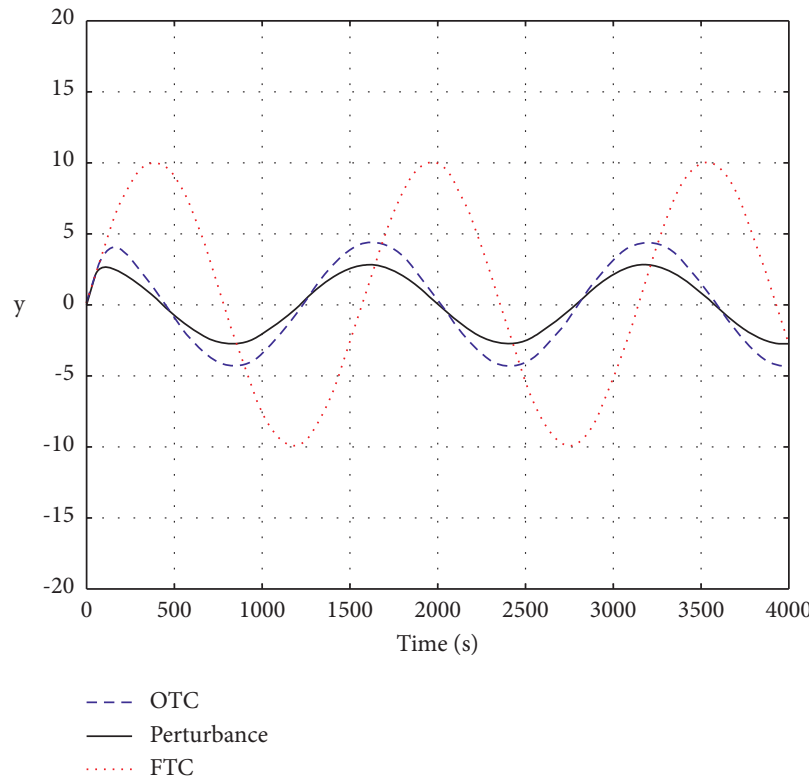

FIgURE 9: Rejected periodic disturbance performance.

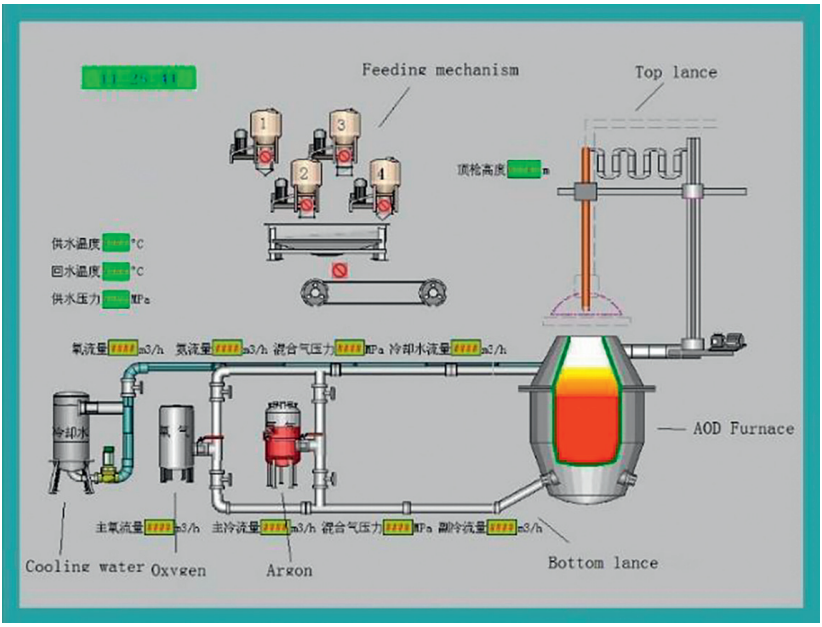

Figure 10: Computer control interface. 


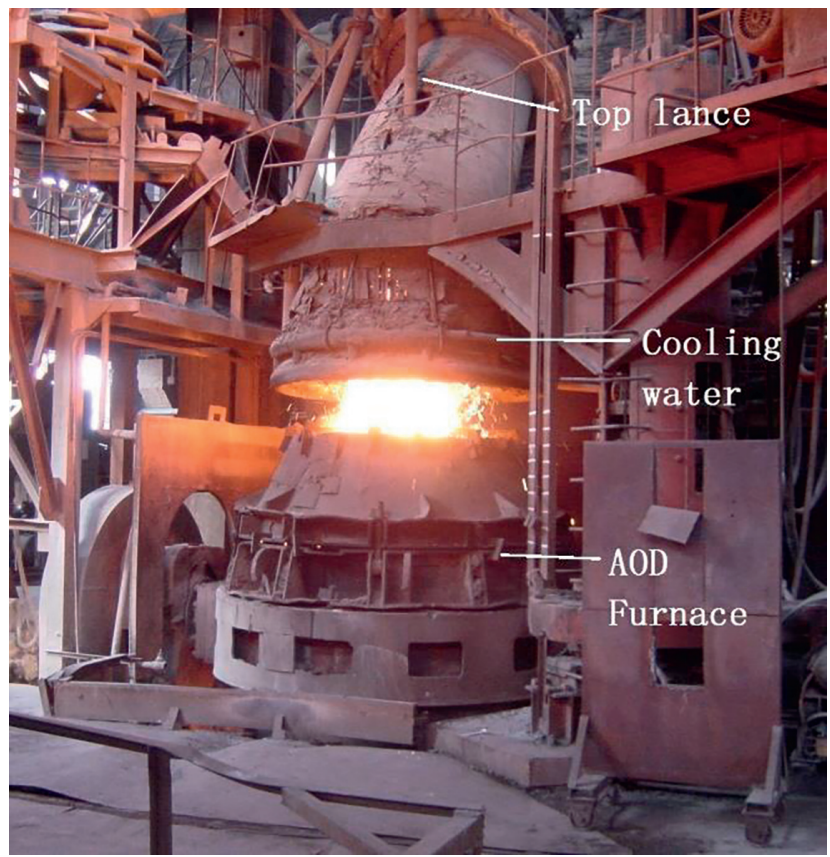

FIgURE 11: The validation heat site.

Table 3: Test data from the 5 ton argon-oxygen refining furnace.

\begin{tabular}{|c|c|c|c|c|c|c|}
\hline $\begin{array}{l}\text { Refining } \\
\text { no. }\end{array}$ & $\begin{array}{l}\text { Initial mass } \\
(\mathrm{t})\end{array}$ & $\begin{array}{c}\text { Initial temperature } \\
\left({ }^{\circ} \mathrm{C}\right)\end{array}$ & $\begin{array}{c}\text { Initial carbon content } \\
(\text { mass \%) }\end{array}$ & $\begin{array}{c}\text { Final temperature } \\
\left({ }^{\circ} \mathrm{C}\right)\end{array}$ & $\begin{array}{c}\text { Endpoint carbon content } \\
(\text { mass \%) }\end{array}$ & $\begin{array}{l}\text { Unit refining time } \\
(\mathrm{min})\end{array}$ \\
\hline $1 \#$ & 4.75 & 1413 & 8.31 & 1706 & 0.45 & 15.58 \\
\hline 2\# & 4.55 & 1403 & 8.35 & 1712 & 0.51 & 14.07 \\
\hline 3\# & 3.54 & 1394 & 7.98 & 1697 & 0.49 & 17.51 \\
\hline $4 \#$ & 4.98 & 1436 & 8.14 & 1709 & 0.49 & 12.65 \\
\hline 5\# & 5.04 & 1428 & 8.34 & 1702 & 0.52 & 12.90 \\
\hline $6 \#$ & 4.63 & 1411 & 8.06 & 1704 & 0.51 & 14.67 \\
\hline 7\# & 4.13 & 1419 & 7.86 & 1704 & 0.47 & 13.80 \\
\hline 8\# & 3.89 & 1388 & 8.42 & 1707 & 0.52 & 15.94 \\
\hline 9\# & 4.37 & 1410 & 8.11 & 1699 & 0.49 & 14.42 \\
\hline $10 \#$ & 4.81 & 1422 & 8.33 & 1705 & 0.48 & 13.51 \\
\hline
\end{tabular}

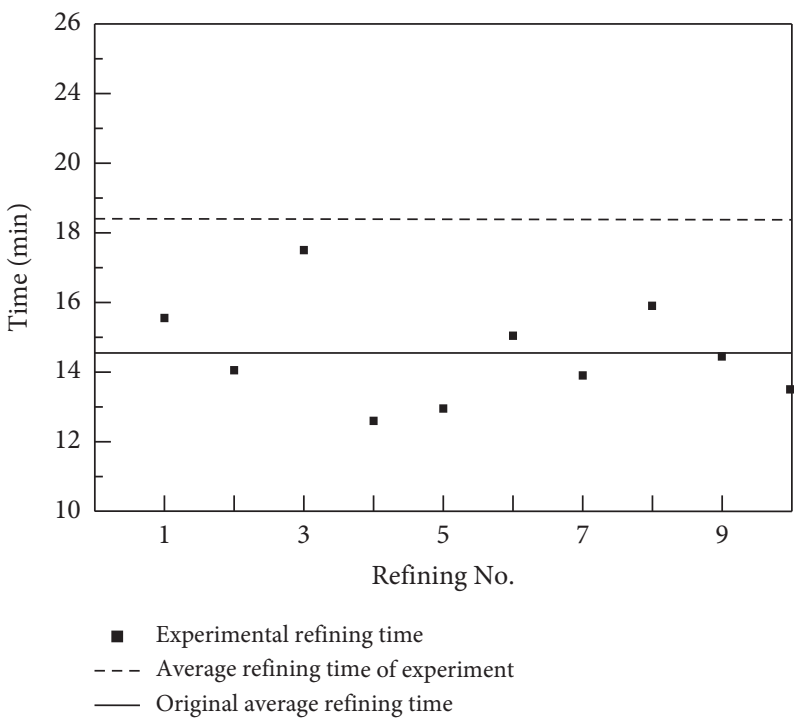

FIgURE 12: Comparison of smelting times. 
method, which resulted in an improvement of the actual production efficiency.

\section{Conclusion}

The present work proposes an improved IMC system to regulate the AOD furnace refining progress. This control system comprises of a piecewise linearized transfer function and an improved internal model controller based on optimized time constant of the filter. The simulation analysis shows that the filtering time parameter optimizer improves the controller's response time, stability, and anti-interference ability. Ten production tests using 5 ton argon-oxygen refining furnace are performed. The experimental data show that the improved IMC method can shorten the average melting time by $21.27 \%$ compared with the original control method. It can effectively improve the actual production efficiency and reduce energy consumption.

\section{Data Availability}

The data used to support the findings of this study are available from the corresponding author upon request.

\section{Conflicts of Interest}

The authors declare that they have no conflicts of interest.

\section{Acknowledgments}

This research was funded by the National Natural Science Foundation of China (51374040) and the Science Research Foundation of Education Department of Jilin Province (no. JJKH20210740 KJ).

\section{References}

[1] M. Morari and E. Zafiriou, Robust Process Control, Prentice Hall, Englewood Cliffs. NY, 1989.

[2] V.-V. Visuri, M. Järvinen, A. Kärnä et al., “A mathematical model for reactions during top-blowing in the AOD process: validation and results," Metallurgical and Materials Transactions $B$, vol. 48, no. 3, pp. 1868-1884, 2017.

[3] J.-H. Wei and D.-P. Zhu, "Mathematical modeling of the argon-oxygen decarburization refining process of stainless steel: Part I. Mathematical model of the process," Metallurgical and Materials Transactions B, vol. 33, no. 1, pp. 111-119, 2002.

[4] H. E. Dong-feng, F. He, A. Xu, and T. Nai-yuan, "On-line liquid steel temperature control for the steelmaking-continuous casting process," Journal of University of Science and Technology Beijing, vol. 36, no. S1, pp. 200-206, 2014.

[5] N. Khanduja and B. Bhushan, "Comparative control study of CSTR using different methodologies: MRAC, IMC-PID, PSOPID, and hybrid BBO-FF-PID, studies in big data," AI and Machine Learning Paradigms for Health Monitoring System, vol. 86, pp. 407-417, 2021.

[6] S. Saxena and Y. Hote, "Advances in internal model control technique: a review and future prospects," IETE Technical Review, vol. 29, no. 6, pp. 461-472, 2012.

[7] K. Kemin Zhou and Z. Zhang Ren, "A new controller architecture for high performance, robust, and fault-tolerant control," IEEE Transactions on Automatic Control, vol. 46, no. 10, pp. 1613-1618, 2001.

[8] M. Ali, J. A. Paulson, and R. D. Braatz, "An internal model control design method for failure-tolerant control with multiple objectives," Computers \& Chemical Engineering, vol. 140, p. 106955, 2020.

[9] M. Jiang, B. Jiang, and Q. Wang, "Internal model control for rank-deficient system with time delays based on damped pseudo-inverse," Processes, vol. 7, no. 5, p. 264, 2019.

[10] Z. Qiu, J. Sun, M. Jankovic, and M. Santillo, "LMI stabilityconstrained identification for composite adaptive internal model control," IEEE Transactions on Automatic Control, vol. 64, no. 12, pp. 5039-5050, 2019.

[11] T. Wu, W. Yu, and L. Guo, "A study on use of hybrid energy storage system Along with variable filter time constant to smooth DC power fluctuation in microgrid," IEEE ACCESS, vol. 7, pp. 175377-175385, 2019.

[12] C. Brosilow and M. Tong, "Inferential control of processes: Part II. The structure and dynamics of inferential control systems," AIChE Journal, vol. 24, no. 3, pp. 492-500, 1978.

[13] Y. Yu, D. Wang, J. Li, M. Li, and Z. Xue, "Effect of cooling conditions on the leachability of chromium in $\mathrm{Cr} 2 \mathrm{O} 3$ containing steelmaking slag," Journal of the South African Institute of Mining and Metallurgy, vol. 118, no. 5, pp. 539-543, 2018.

[14] C. Xu and Z. Wang, "The new technology OF low carbono extra low carbon ferroalloy smelting," FERRO - ALLOYS, vol. 49, no. 04, pp. 1-4, 2018.

[15] C. -J. Guan and W. You, "A nonlinear prediction model, incorporating mass transfer theory and expert rules, for refining low-carbon ferrochrome," Journal of the South African Institute of Mining and Metallurgy, vol. 120, no. 12, pp. 671-680, 2020.

[16] H. Weitz and A. M. Garbers-Craig, "Evaluation of the furnace method for the production of low carbon ferrochrome," Mineral Processing and Extractive Metallurgy Review, vol. 37, no. 3, pp. 168-178, 2016.

[17] Z. Yin, C. Bai, N. Du, C. Du, and J. Liu, "Research on internal model control of induction motors based on luenberger disturbance observer," IEEE Transactions on Power Electronics, vol. 36, no. 7, pp. 8155-8170, 2021.

[18] H. R. Ossareh, S. Wisotzki, J. Buckland Seeds, and M. Jankovic, "An internal model control-based approach for characterization and controller tuning of turbocharged gasoline engines," IEEE Transactions on Control Systems Technology, vol. 29, no. 2, pp. 866-875, 2021.

[19] G. Wang and A. " Design of Multivariable Inferential Control System, Journal of Tsinghua University, vol. 31, no. 04, pp. 52-60, 1991.

[20] J. Zhang and R. Agustriyanto, "Multivariable inferential feedforward control," Industrial \& Engineering Chemistry Research, vol. 42, no. 18, pp. 4186-4197, 2003.

[21] N. Zhang, Q. Wang, and Z. Zhang, "A close loop analysis of the inferential control system," Journal of Guangdong University of Technology, vol. 15, no. 02, pp. 26-29, 1998.

[22] E. G. Abarinov and D. A. Litvinov, "Effect of the time constants of filters on the error of a compensating meter that measures orthogonal components," Measurement Techniques, vol. 44, no. 1, pp. 71-76, 2001.

[23] R. A. Harvey, "The selection of optimum time constants for RC filters with random signals," IEEE Transactions on Nuclear Science, vol. 9, no. 2, pp. 85-90, 1962.

[24] Ji-liang Shang, W. A. N. G. Xiao-yan, and J. I. A. N. G. Jinxing, "Fuzzy self-adjusting of filter time constant of internal 
model control and application," Control and Instruments in Chemical Industry, vol. 35, no. 02, pp. 7-9, 2008.

[25] J. Kennedy and R. C. Eberhart, "Particle swarm optimization," in Proceedings of the IEEE International Conference on Neural Networks, pp. 1942-1948, IEEE, Perth, Australia, July1995.

[26] A. Omer Shuaib, "Muawia mohamed ahmed. International journal of innovative research in science," Engineering and Technology, vol. 3, no. 8, pp. 15060-15067, 2014.

[27] N. Ahmad, M. M. Ebadzadeh, and R. Safabakhsh, "A novel particle swarm optimization algorithm with adaptive inertia weight," Applied Soft Computing, vol. 11, no. 4, pp. 3658-3670, 2011.

[28] L. I. Lei and N. I. U. Hong-fei, L. I. N. Jing-jun, C. H. E. Chang-jin, and L. I. N. Xiao-mei, Quantitative analysis of carbon in low-carbon alloy steel by collinear DPLIBS," Spectroscopy and Spectral Analysis, vol. 38, no. 09, pp. 2951-2956, 2018.

[29] G. Martins Fernando, "Tuning PID controllers using the ITAE criterion," International Journal of Engineering Education, vol. 21, no. 5, pp. 867-873, 2005.

[30] W. E. I. Bing-kun, Y. O. U. Wen, and C.-jun Guan, "Endpoint control system for argon-oxygen refining of low carbon ferrochrome based on internal model control," Metallurgical Industry Automation, vol. 44, no. 1, pp. 55-59, 2020.

[31] V.-V. Visuri, M. Järvinen, A. Kärnä et al., "A mathematical model for reactions during top-blowing in the AOD process: derivation of the model," Metallurgical and Materials Transactions B, vol. 48, no. 3, pp. 1850-1867, 2017.

[32] W. E. I. Ji-He, Y. Cao, Z. H. U. Hong-Li, and C. H. I. He-Bing, "Mathematical modeling study on combined side and top blowing AOD refining process of stainless steel," ISIJ International, vol. 51, no. 3, pp. 365-374, 2011.

[33] N. A. I. Andersson, A. Tilliander, L. T. I. Jonsson, and P. G. Jönsson, "Preliminary investigation of influence of temperature on decarburisation using fundamental AOD model," Ironmaking and Steelmaking, vol. 40, no. 7, pp. 551-558, 2013. 